\title{
Effects of Sonidegib Following Dose Reduction and Treatment Interruption in Patients with Advanced Basal Cell Carcinoma During 42-Month BOLT Trial
}

\author{
Karl Lewis (D) - Reinhard Dummer - Aaron S. Farberg • \\ Alexander Guminski · Nicholas Squittieri · Michael Migden
}

Received: July 22, 2021 / Published online: October 20, 2021

(C) The Author(s) 2021

\section{ABSTRACT}

Introduction: Sonidegib is a Hedgehog pathway inhibitor approved to treat locally advanced basal cell carcinoma and, depending on regulatory approval, metastatic basal cell carcinoma. Results from the BOLT study demonstrated robust efficacy and continued tolerability through 42 months. This analysis evaluated the impact of sonidegib dose reductions and interruptions in patients with advanced basal cell carcinoma through 42 months.

Supplementary Information The online version contains supplementary material available at https://doi. org/10.1007/s13555-021-00619-4.

K. Lewis $(\bowtie)$

Anschutz Medical Campus, University of Colorado Cancer Center, 12801 East 17th Avenue, Aurora, CO 80045, USA

e-mail: Karl.lewis@cuanschutz.edu

\section{R. Dummer}

Department of Dermatology, Skin Cancer Center, University Hospital, University of Zürich, Zurich, Switzerland

A. S. Farberg

Division of Dermatology, Baylor University Medical Center, Dallas, TX, USA

A. Guminski

Department of Medical Oncology, Royal North Shore

Hospital, St Leonards, Australia
Methods: BOLT was a randomized, doubleblind, multicenter, phase 2 study. Adults with no previous Hedgehog pathway inhibitor therapy were randomized $1: 2$ to sonidegib 200 or $800 \mathrm{mg}$ once daily. Primary endpoint was objective response rate. Dose modifications were permitted in patients unable to tolerate the dosing schedule or if a treatment-related adverse event was suspected.

Results: The incidence of dose interruptions was similar between the 200- and 800-mg groups (68.4\% vs $65.3 \%$, respectively). Dose reductions occurred more frequently in patients receiving sonidegib $800 \mathrm{mg} \quad(36.7 \%)$ than $200 \mathrm{mg}$ (16.5\%). Overall response rate for all patients receiving sonidegib $200 \mathrm{mg}$ daily was $48.1 \%$ and was similar to those of patients

A. Guminski

The University of Sydney, Sydney, Australia

N. Squittieri

Medical Affairs Oncology, Sun Pharmaceutical Industries, Inc., Princeton, NJ, USA

M. Migden

Division of Internal Medicine, and Head and Neck

Surgery, Division of Surgery, Department of

Dermatology, University of Texas MD Anderson

Cancer Center, Houston, TX, USA 
without dose reduction or interruption (48.5\%) and patients with at least one dose reduction or interruption (46.2\%).

Conclusion: Dose reductions and interruptions were practical and did not impact the efficacy of sonidegib. In patients with advanced basal cell carcinoma who necessitate long-term treatment, dose interruptions may be beneficial for continued treatment and disease control.

Trial registration: ClinicalTrials.gov identifier, NCT01327053.

Keywords: Basal cell carcinoma; Dose interruption; Dose reduction; Hedgehog pathway inhibitor; Sonidegib

\section{Key Summary Points}

\section{Why carry out this study?}

Hedgehog pathway inhibitors (HHIs) inhibit aberrant Hedgehog signaling found in most cases of basal cell carcinoma (BCC) and are one of the few mechanistic-based pharmacologic treatment options available for patients with advanced BCC.

Adverse events are a substantial limiting factor for treatment duration with HHIs.

\section{What was learned from the study?}

Results from the 42-month BOLT study on sonidegib, an HHI, demonstrate that dose reductions and interruptions were well tolerated in patients and did not compromise the efficacy of sonidegib.

Dose interruptions may be a valuable approach for sustained treatment and disease control.

\section{INTRODUCTION}

Basal cell carcinoma (BCC) is the most common malignancy and form of skin cancer worldwide $[1,2]$. Advanced BCC (aBCC) can be characterized either as locally advanced BCC (laBCC) or metastatic BCC (mBCC); treatment options for patients with aBCC are limited [3].

Inhibition of the Hedgehog signaling pathway offers patients with aBCC a promising treatment option $[1,4]$. Sonidegib, a Hedgehog pathway inhibitor (HHI), selectively targets Smoothened and is approved for the treatment of laBCC that has recurred following surgery or radiation therapy, or for patients who are not candidates for surgery or radiation therapy [5-8].

Results from the pivotal Basal Cell Carcinoma Outcomes with LDE225 (sonidegib) Treatment (BOLT) trial (NCT01327053) demonstrated durable efficacy of sonidegib to treat laBCC and mBCC [9-11]. At the final 42-month analysis, objective response rate (ORR) (95\% confidence interval [CI]) was $48.1 \%$ $(36.7-59.6 \%)$ vs $41.7 \%(33.8-50.0 \%)$ for the 200- and 800-mg groups, respectively [9]. In BOLT, adverse events (AEs) were the main cause of discontinuations $[9,10]$. Accordingly, treatment interruption or dose modification is an important aspect of HHI treatment for BCC in order for clinicians to best manage their patients' therapeutic courses. Here, we examine efficacy and safety outcomes associated with sonidegib treatment interruption or dose reduction in patients with aBCC enrolled in the BOLT trial.

\section{METHODS}

\section{Study Design}

The study design for BOLT has been previously described (Fig. S1 in the supplementary material) [9-11]. The primary efficacy endpoint was ORR; secondary endpoints included duration of response (DOR) and progression-free survival (PFS).

Dose modifications were allowed for patients who were unable to tolerate the protocol-specified dosing schedule or in the event of an adverse reaction suspected to be related to the study drug. In patients with study drug withheld because of suspected toxicity, scheduled visits and assessments continued with the 


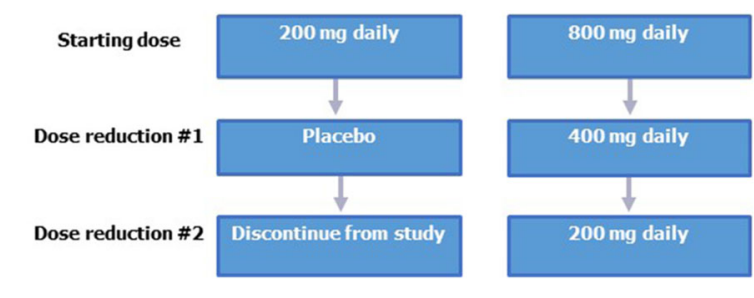

Fig. 1 Dose modification steps for sonidegib

exception of study drug dosing. In patients randomized to the 800-mg dose, a maximum of two dose reductions were permitted; if there was a need for further dose reduction, the patient was discontinued from study treatment (Fig. 1). A maximum of one dose reduction (to placebo treatment) was allowed for patients receiving the 200-mg dose, after which the patient was discontinued from study treatment if there was a need for further dose reduction. For dose interruptions, if the patient experienced the same toxicity following resumption of treatment, regardless of duration, the second reinitiation of study drug was resumed at a lower dose. Any dose interruption that exceeded 21 days from the previous dose resulted in discontinuation from study treatment. In patients who discontinued study treatment because of an $\mathrm{AE}$ or laboratory abnormality, assessments were continued until resolution of the event. All dosage interruptions and reductions were recorded in the Dosage Administration Record Case Report Form, as appropriate. Specific clinical strategies were established for managing AEs (Table 1).

All patients provided written informed consent prior to the conduction of any studyspecific procedures. The study protocol and all amendments were approved by the institutional review board/independent ethics committee for each center (Table S1 in the supplementary material). This study was carried out in accordance with the ethical principles of the Declaration of Helsinki.

\section{Assessments}

All patients received sonidegib 200 or $800 \mathrm{mg}$ once daily until progressive disease (PD), intolerable toxicity, withdrawn consent, study discontinuation, or death. ORR was assessed applying Response Evaluation Criteria in Solid Tumors (RECIST) v1.1 in patients with mBCC and modified RECIST in patients with laBCC. Safety assessments included monitoring and recording AEs and frequent monitoring of hematology, clinical chemistry, and electrocardiograms. The statistical methods were reported previously [9-11].

\section{RESULTS}

\section{Patient Disposition and Disease Characteristics}

Of 230 patients enrolled and randomized, 79 received sonidegib $200 \mathrm{mg}$ and 151 sonidegib $800 \mathrm{mg}$. At study completion, 11 (4.8\%) patients remained on treatment (6 in the 200-mg group and 5 in the 800-mg group); median follow-up was 50.2 months. Most frequent study discontinuation causes included AEs (34.8\%), PD (23.0\%), withdrawal by patient $(18.7 \%)$, and physician decision $(10.4 \%)$, consistent with previous reports $[10,11]$. Patient demographics and baseline disease characteristics were previously described (Table $\mathrm{S} 2$ in the supplementary material) [11].

\section{Dose Reductions and Treatment Interruptions}

Dose reductions and interruptions were predominantly attributed to AEs and consistent with the 30-month analysis results [10]. Through 42 months of sonidegib treatment, treatment interruptions were more common than dose reductions. The incidence of dose interruptions was comparable between the 200and $800-\mathrm{mg}$ groups $(68.4 \%$ vs $65.3 \%$, respectively; Table 2), while dose reductions were less common in the 200 -mg group $(16.5 \%)$ vs the 800 -mg group (36.7\%). 
Table 1 Recommended dose modifications and dose interruptions for suspected treatment-related muscle toxicity

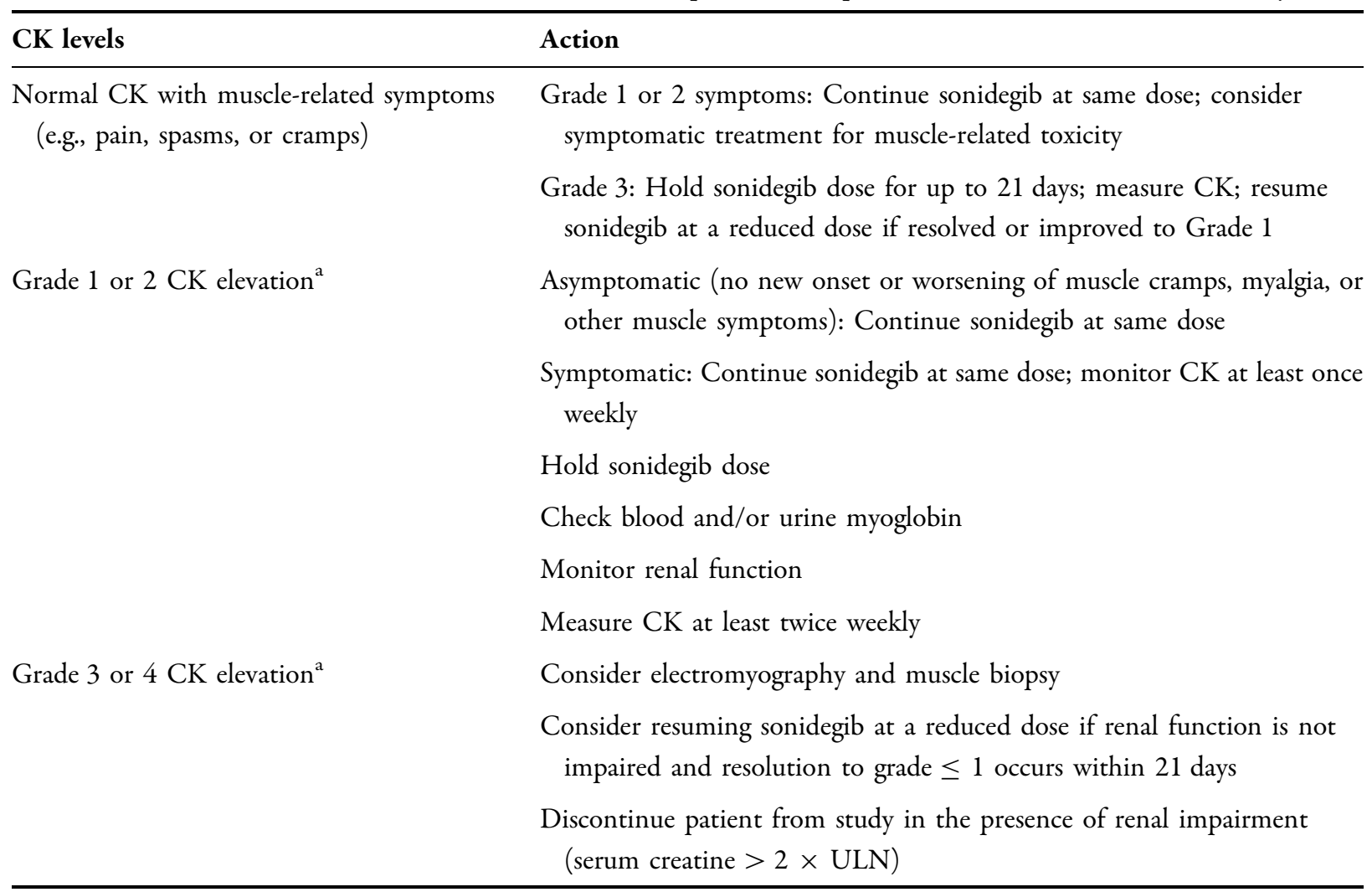

$C K$ creatine kinase, $U L N$ upper limit of normal

${ }^{a}$ Graded according to National Cancer Institute Common Terminology Criteria for Adverse Events, v4.03 [15]

\section{Effect of Sonidegib Dose Reductions and Treatment Interruptions on Efficacy Endpoints}

For patients receiving $200 \mathrm{mg}$, ORRs were comparable between all patients $(48.1 \%)$ and subgroups of patients with at least one dose reduction or interruption $(46.2 \%)$ and without dose reductions or interruptions $(48.5 \%$, Table 3). In patients with at least one dose reduction or interruption receiving sonidegib $800 \mathrm{mg}$, ORRs were higher compared with patients receiving the 200-mg dose who also had at least one dose reduction or interruption, although no statistical comparison was performed to determine significance. Overall, for all patients receiving sonidegib $800 \mathrm{mg}$, median DOR (95\% CI) (23.3 [12.2-29.6] months) was comparable to that for patients with at least one dose reduction or interruption (24.8 [not estimable] months) (Table 3). However, in patients receiving sonidegib $200 \mathrm{mg}$, the effect of dose reduction or interruption on DOR was not able to be determined, given the small number of events.

Similar to DOR efficacy outcomes, median PFS (95\% CI) for all patients receiving sonidegib $800 \mathrm{mg}$ (21.5 [16.1-28.4] months) was similar to patients with at least one dose reduction or interruption receiving the $800-\mathrm{mg}$ dose (24.9 [16.6-42.8] months, Table 3). Moreover, in patients receiving sonidegib $800 \mathrm{mg}$, median PFS (95\% CI) was higher in patients with at least one dose reduction or interruption (29.3 [19.3-43.3] months) compared with patients without a dose reduction or interruption (21.5 [13.2-33.4] months). As with DOR outcomes, median PFS in patients receiving sonidegib 
Table 2 Dose reduction and treatment interruptions in patients at 42 months

\begin{tabular}{|c|c|c|c|}
\hline & $\begin{array}{l}\text { Sonidegib } 200 \mathrm{mg} \text { daily } \\
(n=79)\end{array}$ & $\begin{array}{l}\text { Sonidegib } 800 \mathrm{mg} \text { daily } \\
(n=151)\end{array}$ & $\begin{array}{l}\text { All patients } \\
(N=230)\end{array}$ \\
\hline Patients treated, $n$ & 79 & 150 & 229 \\
\hline Patients with any dose reduction, $n(\%)$ & $13(16.5)$ & $55(36.7)$ & $68(29.7)$ \\
\hline 1 reduction & $13(16.5)$ & $44(29.3)$ & $57(24.8)$ \\
\hline 2 reductions & 0 & $11(7.3)$ & $11(4.8)$ \\
\hline Reasons for dose reduction, $n$ & $13^{\mathrm{a}}$ & $55^{\mathrm{a}}$ & $68^{\mathrm{a}}$ \\
\hline Adverse event & 12 & 57 & 69 \\
\hline Dosing error & 1 & 3 & 4 \\
\hline Lack of efficacy & 0 & 1 & 1 \\
\hline \multicolumn{4}{|l|}{ Days full dose received, $\%$} \\
\hline Median, range & $99.1(8.1-100)$ & $94.2(2.6-100)$ & $97.6(2.6-100)$ \\
\hline Patients with any interruption in treatment, $n(\%)$ & $54(68.4)$ & $98(65.3)$ & $152(66.4)$ \\
\hline 1 interruption & $19(24.1)$ & $34(22.7)$ & $53(23.1)$ \\
\hline$\geq 2$ interruptions & $35(44.3)$ & $64(42.7)$ & $99(43.2)$ \\
\hline \multicolumn{4}{|l|}{ Days of sonidegib treatment, $\%$} \\
\hline Median, range & $99.1(76.7-100)$ & $97.8(46.6-100)$ & $98.5(46.6-100)$ \\
\hline Reasons for treatment interruption, $n(\%)$ & $54^{\mathrm{a}}$ & $98^{\mathrm{a}}$ & $152^{\mathrm{a}}$ \\
\hline Adverse event & $31(39.2)$ & $77(51.3)$ & $108(47.2)$ \\
\hline Dosing error & $28(35.4)$ & $47(31.3)$ & $75(32.8)$ \\
\hline Technical issue & $18(22.8)$ & $24(16.0)$ & $42(18.3)$ \\
\hline Dispensing error & 0 & $1(0.7)$ & $1(0.4)$ \\
\hline
\end{tabular}

${ }^{a}$ Patient with multiple reasons for dose change or interruption is only counted once in the total row

$200 \mathrm{mg}$ with at least one dose reduction or interruption was unable to be calculated because of the low number of events.

\section{Safety}

As described previously, most AEs were manageable and consistent with previous analyses [9-11]. Overall, AEs were predominantly Grade 1 or 2 in patients receiving sonidegib $200 \mathrm{mg}$. Grade 3-4 AEs were reported in 43.0\% and $64.0 \%$ of patients receiving sonidegib 200 and $800 \mathrm{mg}$, respectively. In addition, Grade 3-4 AEs resulted in discontinuation in
$13.9 \%$ and $14.7 \%$ of patients in the 200 - and 800-mg dosing groups, respectively. In patients with dose reductions or interruptions, AEs were primarily reversible.

Most frequent AEs (>5\%) leading to dose reductions or interruptions in the 200-mg group were elevated serum creatine kinase (CK; 6.3\%), nausea $(6.3 \%)$, vomiting $(6.3 \%)$, diarrhea $(5.1 \%)$, and increased lipase $(5.1 \%)$. In the 800-mg group, AEs (>5\%) leading to dose reductions or interruptions consisted of muscle spasms $(18.7 \%)$, nausea (12.7\%), elevated serum CK $(12.0 \%)$, dysgeusia $(8.0 \%)$, and vomiting (8.0\%). 
Table 3 Objective response rates, duration of response, and progression-free survival by central review at 42 months in patients with advanced basal cell carcinoma with and without dose reduction or interruption

\section{Sonidegib $200 \mathrm{mg}$ daily \\ $(n=79)$}

Objective response rate

All patients (laBCC + mBCC)

Events/responders, $n / N$

ORR (95\% CI)

No dose reduction or interruption

Events/responders, $n / N$

ORR (95\% CI)

$\geq 1$ dose reduction or interruption

Events/responders, $n / N$

ORR (95\% CI)

Patients with laBCC

Events/responders, $n / N$

ORR (95\% CI)

No dose reduction or interruption

Events/responders, $n / N$

ORR (95\% CI)

$\geq 1$ dose reduction or interruption

Events/responders, $n / N$

ORR (95\% CI)

Duration of response

$$
\begin{aligned}
& \text { All patients (laBCC }+\mathrm{mBCC}) \\
& \text { Events/responders, } n / N \\
& \text { Median, months }(95 \% \mathrm{CI})
\end{aligned}
$$

$13 / 38$

26.1 (NE)

$6 / 13$

$46.2 \%(19.2-74.9)$

$37 / 66$

$56.1 \%(43.3-68.3)$

$31 / 54$

$57.4 \%(43.2-70.8)$

$6 / 12$

$32 / 48$

$50.0 \%(21.1-78.9)$
Sonidegib $800 \mathrm{mg}$ daily $(n=151)$

No dose reduction or interruption

Events/responders, $n / N$

$12 / 32$

$13 / 31$

Median, months (95\% CI)

24.0 (NE)

$14.7(8.3-26.4)$

$\geq 1$ dose reduction or interruption

Events/responders, $n / N$

$1 / 6$

$11 / 32$

Median, months (95\% CI)

NE (NE) 
Table 3 continued

Sonidegib200 mg

daily $(n=79)$

Patients with laBCC

Events/responders, $n / N$

Median, months (95\% CI)

$12 / 37$

26.1 (NE)

23/59

No dose reduction or interruption

Events/responders, $n / N$

$11 / 31$

$26.1(\mathrm{NE})$

Median, months (95\% CI)

$\geq 1$ dose reduction or interruption

Events/responders, $n / N$

$1 / 6$

NE (NE)

$12 / 27$

$11 / 32$
Sonidegib800 mg

daily $(n=151)$

$14.7(8.8-26.4)$

$24.8(\mathrm{NE})$

Progression-free survival

All patients (laBCC + mBCC)

Events/responders, $n / N$

$25 / 79$

$22.1(14.4-33.1)$

Median, months (95\% CI)

No dose reduction or interruption

Events/responders, $n / N$

Median, months (95\% CI)

$\geq 1$ dose reduction or interruption

Events/responders, $n / N$

Median, months (95\% CI)

Patients with laBCC

Events/responders, $n / N$

Median, months (95\% CI)

No dose reduction or interruption

Events/responders, $n / N$

Median, months (95\% CI)

$\geq 1$ dose reduction or interruption

Events/responders, $n / N$

Median, months (95\% CI)

\section{$22 / 66$}

$22.1(14.4-30.7)$

$3 / 13$

NE (NE)

$17 / 66$

$22.1(\mathrm{NE})$

$15 / 54$

$22.1(14.4-39.6)$

$2 / 12$

NE (NE)
$46 / 151$

$21.5(16.1-28.4)$

28/96

$16.7(12.1-28.4)$

$18 / 55$

$24.9(16.6-42.8)$

$33 / 128$

$24.9(19.2-33.4)$

20/80

$21.5(13.2-33.4)$

$13 / 48$

$29.3(19.3-43.3)$

Median DOR and PFS were calculated using the Kaplan-Meier method

$B C C$ basal cell carcinoma, $C I$ confidence interval, $l a B C C$ locally advanced BCC, $m B C C$ metastatic BCC, $N E$ not estimable, $O R R$ objective response rate 
For patients who experienced Grade $\geq 2$ elevations in serum CK, $14.3 \% \quad(n=2)$ of patients in the 200-mg group and $36.2 \%$ $(n=17)$ of patients in the 800-mg group required dose interruptions within 2 weeks of onset of the AE. Following dose interruption, patients in the 200-mg group received placebo, while for the 800-mg group, 11 of 17 patients resumed at a reduced dose level and 6 patients resumed at $800 \mathrm{mg}$. Overall, the median times to a dose interruption due to Grade $\geq 2$ serum CK elevation were 12.5 days and 18.0 days for patients receiving 200 and $800 \mathrm{mg}$, respectively.

\section{DISCUSSION}

This analysis of the BOLT trial demonstrated robust and continued efficacy of sonidegib in patients with aBCC who required dose reductions and/or interruptions through 42 months of treatment. More patients necessitated treatment interruptions than dose reductions. Importantly, patients with dose reductions or interruptions still showed clinically meaningful ORRs. Notably, patients receiving sonidegib $800 \mathrm{mg}$ that had at least one treatment reduction or interruption had greater ORRs compared with the total patient population as well as patients without dose reductions or interruptions.

While HHIs provide a promising treatment option for patients with aBCC, AEs can be difficult for patients to endure. Therefore, treatment with HHIs needs to maintain a balance between disease control and potential adverse reactions. In this analysis, AEs were mostly Grade 1-2; however, AEs were the primary reason for discontinuation $[10,11]$. Therefore, since AEs are commonly the source of treatment interruptions and discontinuations and may potentially impact disease outcome, treatment interruptions are a frequent approach in patient management, especially with more severe AEs [12].

In a phase 2 study assessing the efficacy and safety of intermittent doses of the HHI vismodegib (Erivedge ${ }^{\circledR}$, Genentech, San Francisco,
CA) in patients with multiple BCCs, treatment interruption did not substantially affect the efficacy of vismodegib [13]. However, 23\% of patients discontinued treatment because of AEs [13]. Notably, an increased number of treatment interruptions were associated with longer median duration of vismodegib treatment [14]. Although there is no direct comparable study evaluating dose interruptions of a prespecified length with sonidegib, the results reported here support the long-term efficacy of sonidegib in patients that experienced treatment interruptions.

It is important to note that for patients receiving the approved dose of sonidegib $200 \mathrm{mg}$ who required a dose reduction, the decreased dose was placebo treatment [5-8]. Consequently, in clinical practice, dose reductions of sonidegib are not a practical option for patients who require dose adjustments due to treatment-related AEs. However, in these patients, treatment interruptions offer a viable option to manage a patient's care while safeguarding continued course of treatment.

Study limitations include small sample size, especially for patients with $\mathrm{mBCC}$, and the effect of sonidegib dose reduction or interruption on DOR and PFS could not be determined because of the low number of responders for the 200-mg dose. Additionally, since patients with recurrent disease following previous therapy with an HHI were excluded from this study, efficacy of sonidegib in these patients is unknown [10].

\section{CONCLUSIONS}

Overall, dose reductions and interruptions were feasible in patients and did not compromise the efficacy of sonidegib. Furthermore, preemptive management of AEs through treatment interruptions may improve tolerability and optimize sonidegib treatment duration. In patients requiring long-term treatment for aBCC, dose interruptions may be a valuable approach for sustained treatment and disease control. 


\section{ACKNOWLEDGEMENTS}

Funding. This study was sponsored and funded by Novartis. The journal's rapid service fee was funded by Sun Pharmaceutical Industries, Inc. (Princeton, NJ, USA). Writing and editorial support for manuscript preparation were provided by Zehra Gundogan, VMD, of AlphaBioCom, LLC, and funded by Sun Pharmaceutical Industries, Inc., Princeton, NJ, USA.

Authorship. All listed authors meet the criteria for authorship set forth by the International Committee for Medical Journal Editors and have significantly contributed to, seen, and approved the final submitted version of the manuscript.

Authorship Contributions. KL, RD, ASF, AG, NS, and MM drafted and critically reviewed the manuscript and approved the final version.

Medical Writing, Editorial, and Other Assistance. Medical writing and editorial assistance were provided by Zehra Gundogan, VMD, of AlphaBioCom, LLC, under the direction of the authors and was funded by Sun Pharmaceutical Industries, Inc.

Disclosures. Karl Lewis has received grants and personal fees from Amgen, Bristol-Myers Squibb, Genentech, GlaxoSmithKline, Merck Sharp \& Dohme, Novartis, and Roche. Reinhard Dummer has participated on advisory boards and consulted for Amgen; Bristol-Myers Squibb; Catalym; Merck Sharpe \& Dohme; Novartis Pharmaceutical Corporation; Pierre Fabre; Roche; Sanofi; Second Genome; Sun Pharmaceutical Industries, Inc.; and Takeda. Aaron S. Farberg has participated on advisory boards and received honoraria from Ortho Dermatologics and Sun Pharmaceutical Industries, Inc. Alexander Guminski has participated on advisory boards for Bristol-Myers Squibb, Pfizer, and Sanofi; received honoraria from Novartis; and received travel support from Astellas; BristolMyers Squibb; and Sun Pharmaceutical Industries, Inc. Nicholas Squittieri is an employee of Sun Pharmaceutical Industries, Inc. Michael
Migden has participated on advisory boards and received honoraria from Genentech; Novartis; Sun Pharmaceutical Industries, Inc.; and Regeneron.

Compliance with Ethics Guidelines. This study was conducted according to the ethical principles of the Declaration of Helsinki. All patients provided informed consent for publication of this report. The study protocol and all amendments were approved by the institutional review board/independent ethics committee for each center (Table S1 in the supplementary material).

Data Availability. All data generated or analyzed during this study are included in this published article/as supplementary information files.

Open Access. This article is licensed under a Creative Commons Attribution-NonCommercial 4.0 International License, which permits any non-commercial use, sharing, adaptation, distribution and reproduction in any medium or format, as long as you give appropriate credit to the original author(s) and the source, provide a link to the Creative Commons license, and indicate if changes were made. The images or other third party material in this article are included in the article's Creative Commons license, unless indicated otherwise in a credit line to the material. If material is not included in the article's Creative Commons license and your intended use is not permitted by statutory regulation or exceeds the permitted use, you will need to obtain permission directly from the copyright holder. To view a copy of this license, visit http:// creativecommons.org/licenses/by-nc/4.0/.

\section{REFERENCES}

1. Bakshi A, Chaudhary SC, Rana M, Elmets CA, Athar M. Basal cell carcinoma pathogenesis and therapy involving hedgehog signaling and beyond. Mol Carcinog. 2017;56(12):2543-57. 
2. Marzuka AG, Book SE. Basal cell carcinoma: pathogenesis, epidemiology, clinical features, diagnosis, histopathology, and management. Yale J Biol Med. 2015;88(2):167-79.

3. Lear JT, Corner C, Dziewulski P, et al. Challenges and new horizons in the management of advanced basal cell carcinoma: a UK perspective. Br J Cancer. 2014;111(8):1476-81.

4. Epstein EH. Basal cell carcinomas: attack of the hedgehog. Nat Rev Cancer. 2008;8(10):743-54.

5. Odomzo (sonidegib capsules). Full Prescribing Information. Sun Pharmaceutical Industries, Inc., Cranbury, NJ, USA.

6. European Medicines Agency. Summary of Product Characteristics, WC500188762. https://www.ema. europa.eu/en/documents/product-information/ odomzo-epar-product-information_en.pdf

7. Swissmedic, Authorization Number 65065. 2015. https://www.swissmedic.ch/swissmedic/de/home/ humanarzneimittel/authorisations/new-medicines/ odomzo-200mg-kapseln-sonidegibum-.html

8. Australian Government Department of Health, ARTG 292262. https://www.ebs.tga.gov.au/ebs/ picmi/picmirepository.nsf/pdf?OpenAgent\&id=CP2017-PI-02511-1\&d=2018030216114622483\&d= 20210929172310101

9. Dummer R, Guminksi A, Gutzmer R, et al. Longterm efficacy and safety of sonidegib in patients with advanced basal cell carcinoma: 42-month analysis of the phase II randomized, double-blind BOLT study. Br J Dermatol. 2020;182(6):1369-78.
10. Lear JT, Migden MR, Lewis KD, et al. Long-term efficacy and safety of sonidegib in patients with locally advanced and metastatic basal cell carcinoma: 30-month analysis of the randomized phase 2 BOLT study. J Eur Acad Dermatol Venereol. 2018;32(3):372-81.

11. Migden MR, Guminski A, Gutzmer R, et al. Treatment with two different doses of sonidegib in patients with locally advanced or metastatic basal cell carcinoma (BOLT): a multicentre, randomised, double-blind phase 2 trial. Lancet Oncol. 2015;16(6):716-28.

12. Lacouture ME, Dréno B, Ascierto PA, et al. Characterization and management of hedgehog pathway inhibitor-related adverse events in patients with advanced basal cell carcinoma. Oncologist. 2016;21(10):1218-29.

13. Dréno B, Kunstfeld R, Hauschild A, et al. Two intermittent vismodegib dosing regimens in patients with multiple basal-cell carcinomas (MIKIE): a randomised, regimen-controlled, doubleblind, phase 2 trial. Lancet Oncol. 2017;18(3): 404-12.

14. Dummer R, Basset-Seguin N, Hansson J, et al. Impact of treatment breaks on vismodegib patient outcomes: exploratory analysis of the STEVIE study. J Clin Oncol. 2015;33(15_suppl):9024.

15. US Department of Health and Human Services. Common Terminology Criteria for Adverse Events (CTCAE). Version 4.0 Published: May 28, 2009 (v4. 03: June 14, 2010). 2016. 